\title{
Quantification of Vertebral Involvement in Metastatic Spinal Disease
}

\author{
Ricardo Vieira Botelho*, Matheus Fernandes de Oliveira and Jose Marcus Rotta
}

\author{
Department of Neurosurgery, Hospital do Servidor Público Estadual de São Paulo, IAMSPE, São Paulo, Brazil
}

\begin{abstract}
Introduction: For patients with a solitary and well-delimitated spinal metastasis that resides inside the vertebral body, without vertebral canal invasion, and who are in good general health with a long life expectancy, en bloc spondylectomy/total vertebrectomy combined with the use of primary stabilizing instrumentation has been advocated. However, clinical experience suggests that these qualifying conditions occur very rarely.

Objective: The purpose of this paper is to quantify the distribution of vertebral involvement in spinal metastases and determine the frequency with which patients can be considered candidates for radical surgery (en bloc spondylectomy).

Methods: Consecutive patients were classified accordingly to Enneking's and Tomita's schemes for grading vertebral involvement of metastases.

Results: Fifty-one (51) consecutive patients were evaluated. Eighty-three percent of patients presented with the involvement of multiple vertebral levels and/or spinal canal invasion.

Conclusion: Because of diffuse vertebral involvement of metastases, no patients in this sample were considered to be candidates for radical spondylectomy of vertebral metastasis.
\end{abstract}

Keywords: Cancer, neoplasm metastasis, prognosis, spine, spondylectomy, surgical procedures.

\section{INTRODUCTION}

In an aging population, chronic degenerative diseases and cancer have been highlighted as major causes of morbidity and mortality [1-8].

Up to $40 \%$ of cancer patients will develop skeletal metastases; the spine, due to its size, contiguity and rich vascularization, is the primary affected bone site [1-3]. Among patients who develop spinal metastases, only 5\%$10 \%$ will develop epidural spinal cord compression, and $10 \%$ of those patients will be symptomatic [1-6]. The number of bone metastases increases with prolonged patient survival, and these metastases are derived from primary tumors originating from the kidney, breast, prostate and other organs [1-9].

The proposed surgical treatment of spinal metastases is controversial. Although non-operative treatments and adjuvant therapies remain important options, surgical strategies that include the entire range of operative procedures should also be considered [9-15].

En bloc spondylectomy/total vertebrectomy accompanied by reconstruction with primary stabilizing instrumentation has been advocated for patients who meet the following criteria: the presence of a solitary and well-delimitated spinal metastasis that resides inside the vertebral body without vertebral canal invasion, good general health, and a long life expectancy [9-12]. However, clinical experience suggests that these qualifying conditions occur very rarely.

*Address correspondence to this author at the Av. Dr. Altino Arantes 390, apto 81, Vila Clementino, São Paulo, São Paulo, 04042002, Brazil; Tel: +5511-981118157; Fax: +5511-45738379;

E-mail: vieira.botelho@uol.com.br
The purpose of this paper is to quantify the distribution of vertebral involvement in spinal metastases and to determine the frequency with which patients requiring admission due to spinal metastasis can be considered as candidates for radical surgery (en bloc spondylectomy).

\section{MATERIALS AND METHODOLOGY}

\section{Vertebral Metastasis Involvement Classification Scheme}

An electronic literature search was performed to reveal the published classifications used to quantify vertebral metastasis involvement. The following search strategy was used: ("spine"[MeSH Terms] OR "spine"[All Fields] OR "vertebral"[All Fields]) AND ("neoplasm metastasis"[MeSH Terms] OR ("neoplasm"[All Fields] AND "metastasis"[All Fields]) OR "neoplasm metastasis"[All Fields] OR "metastasis"[All Fields]) AND ("classification"[Subheading] OR "classification"[All Fields] OR "classification"[MeSH Terms]). Classification schemes that we considered appropriate for grading the involvement of metastatic spinal disease were analyzed, and cross-references for vertebral classification schemes were searched. From these, Enneking, Tomita, Weinstein-Boriani-Biagini (WBB) and Harrington scales for vertebral involvement were initially considered for our quantification of vertebral involvement [4, 14-19].

The WBB classification was excluded from consideration because we deemed it to be extremely compartmentalized and adequate only for slow-growing tumors, such as benign and primary bone tumors. Harrington's classification was designed to evaluate vertebral stability, and although it describes vertebral collapse and stability, it embodies other data that are not specific toward determination of vertebral involvement; thus, this classification system was also excluded from consideration. 
Ultimately, patients were classified accordingly to Enneking's (Fig. 1) and Tomita's (Fig. 2) schemes for vertebral involvement classification.

\section{PATIENTS AND METHODS}

The study sample consisted of patients with vertebral metastases requiring admission consecutively admitted from July 2010 to October 2012 at the Hospital do Servidor
Público Estadual de São Paulo (HSPE). We set the number of patients to be studied as the number that represent a normal sample patient distribution and defined the sample between 30 and 50 patients due to possible losses during study.

This project was approved by the Research and Ethics Committee of HSPE.

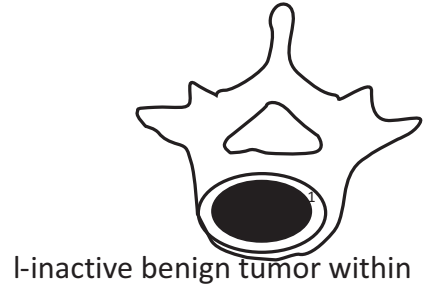
a pseudocapsule.

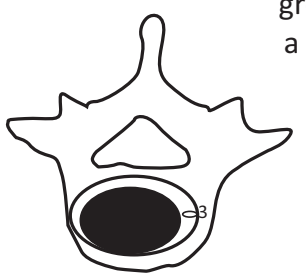

IA- malignant tumor cells within the pseudocapsule

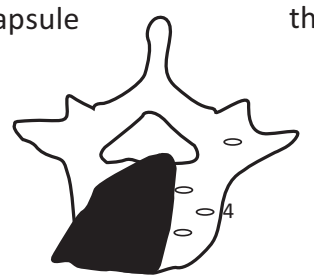

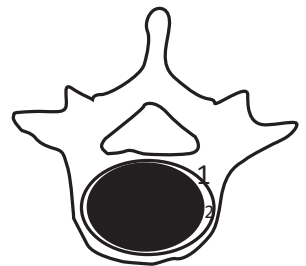

II- benign tumor with growth within a pseudocapsule.

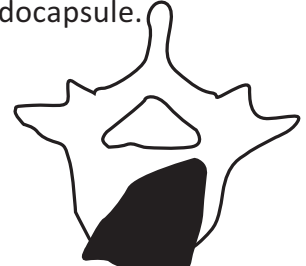

IB- malignant tumor cells beyond the original compartment.

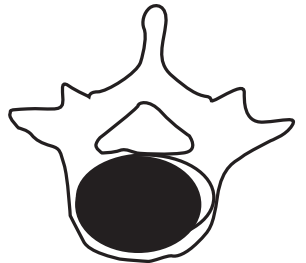

III- aggressive benign tumor growth beyond the pseudocapsule.

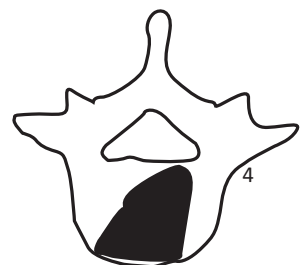

IIA- malignant tumors, local skip metastases.

IIB- malignant tumors, distal skip metastases.

Fig. (1). Diagram based on Enneking's classification of benign tumors. The top three diagrams represent benign tumors and the lower four, malignant tumors. 1, tumor capsule; 2 , tissue reaction; 3 , tumor island within adjacent tissue reaction; 4, skip metastasis.

Intra-Compartimental

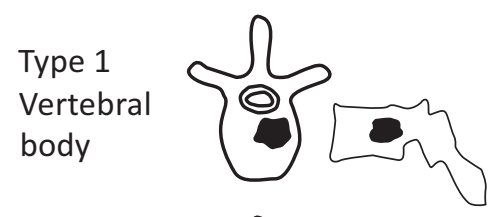

Type 2

Pedicle extension
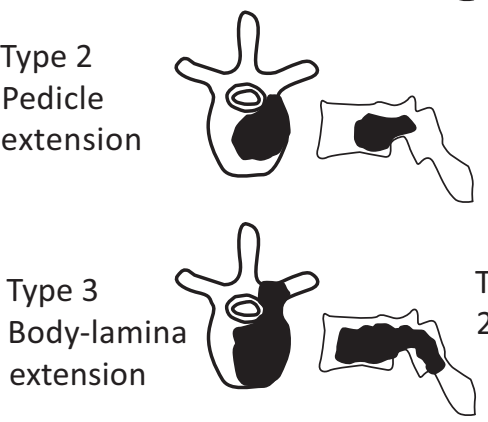

\section{Extra-Compartimental}
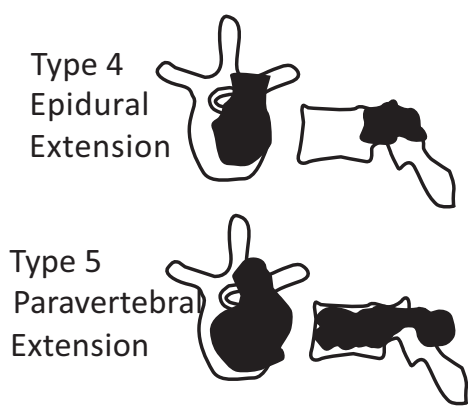

Type 6

2-3 vertebras

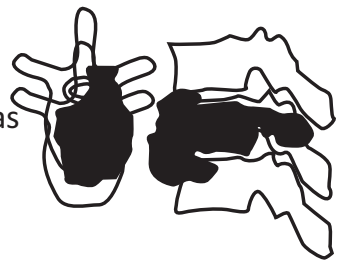

Multiple

Type 7

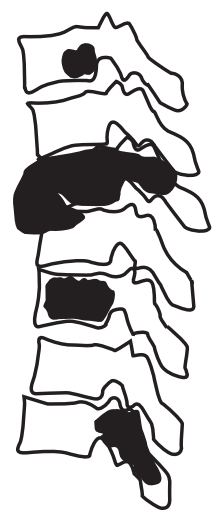

Fig. (2). Diagram based on Tomita's classification of vertebral metastasis. 
The patients received complete clinical and neurological examinations and were classified according to the Karnofsky scale and the Frankel scale, respectively.

\section{STATISTICS}

Numerical data were described as the means \pm standard deviations. Categorical data are presented as percentages. To determine the distribution of our data, the KolmogorovSmirnov Test was used. Student's t-test was used for the paired and unpaired groups as appropriate. The significance level was established as $\mathrm{p}<0.05$.

\section{RESULTS}

Fifty-one consecutive patients with spinal metastases who were admitted to the Hospital do Servidor Público Estadual de São Paulo (HSPE) were evaluated between July 2010 and October 2012. Sixteen patients were female, and 35 were male. The average age was $61.07 \pm 11.78$ for women and $62.74 \pm 10.17$ for men. The ages of the groups did not differ significantly ( $\mathrm{p}>0.05)$.

Of the 51 patients, only 1 was asymptomatic and was referred from the oncology department after an active search for metastases. Fifteen patients presented with spinal pain, 17 with neurological deficits and 18 with both pain and neurological deficits.

All patients were neurologically (Frankel scale; Fig. 3) and clinically (Karnofsky scale; Fig. 4) evaluated. Neurologically, 5 patients presented with a complete deficit (Frankel A), 2 with Frankel B, 19 with Frankel C, 9 with Frankel D and 16 with Frankel E (Fig. 3).

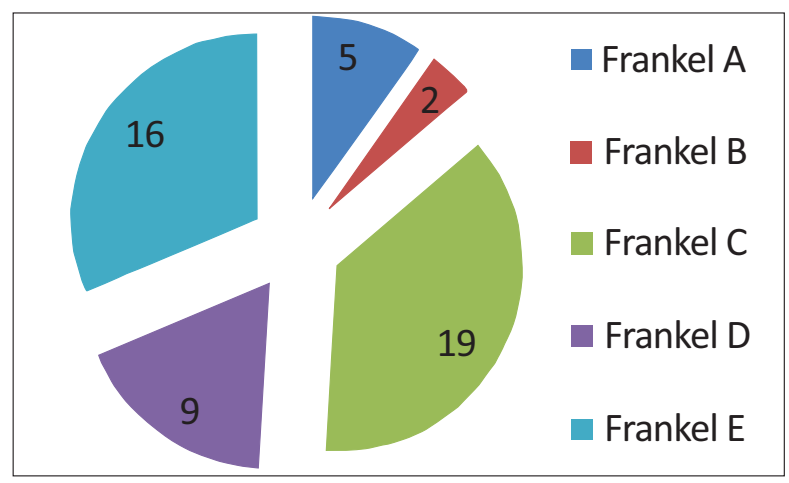

Fig. (3). Neurological patient presentation based on Frankel scale. Grade A: Complete neurological injury with no motor or sensory function clinically detected below the level of the injury. Grade B: Preserved sensation only; no motor function clinically detected below the level of the injury; sensory function remaining below the level of the injury but may include only partial function. Grade C: Preserved motor non-functional. Grade D: Useful motor function below the level of the injury; patient can move lower limbs and walk with or without aid but does not have a normal gait or strength in all motor groups. Grade E: Normal motor functioning.

The KS varied from 30 to 90 . Two patients presented with a KS of 30 , six patients with a score of 40 , eleven patients with a score of 50, sixteen patients with a score of 60 , three patients with a score of 70 , nine patients with a score of 80 and four patients with a score of 90 (Fig. 4).

Vertebral metastases were localized in the thoracic spine in $82 \%$ of cases, the lumbar spine in $50 \%$, the cervical spine in $26 \%$ and the sacral spine in $10 \%$.

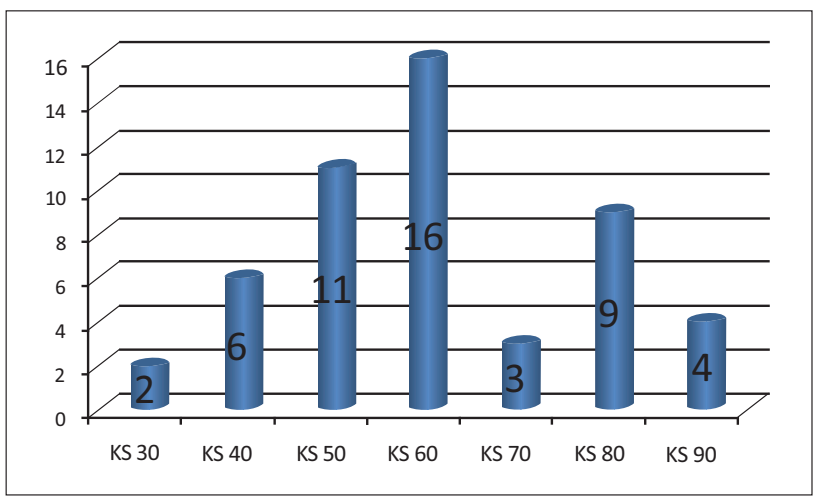

Fig. (4). Number of patients corresponding to each grade of the Karnovsky scale (KS).

All patients had a known histopathological diagnosis (Fig. 5). Twelve were diagnosed with primary tumors in the breast, twelve in the prostate, and four in the lung. Four patients had multiple myeloma, three had colon cancer, and three had non-Hodgkin's lymphoma. Bladder, kidney and larynx cancers were reported by one patient each.

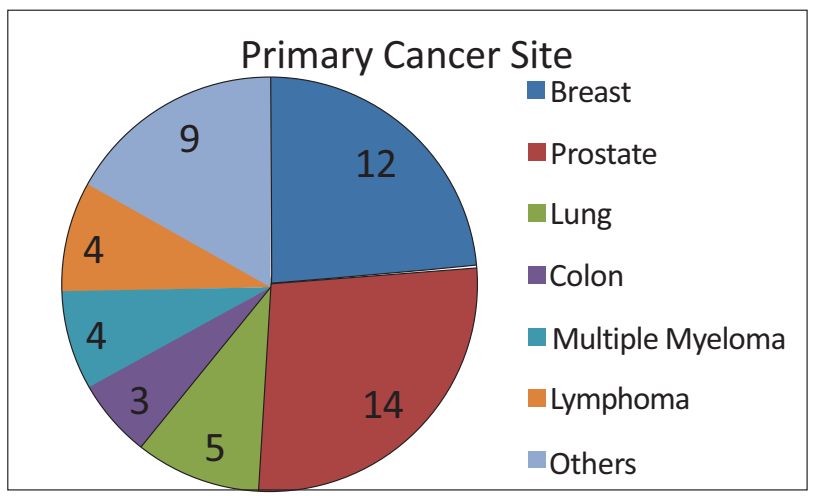

Fig. (5). Number of patients with vertebral metastasis from each primary tumor type.

\section{VERTEBRAL SPINE INVOLVEMENT}

\section{Enneking's Classification}

All of the patients had vertebral involvement above Enneking's IIA level (Fig. 6). Each patient had a tumor extending abroad from the cortical vertebral body limits. Due to the extension of vertebral body involvement, it was not possible to identify skip metastases inside the vertebral body as has been performed for benign spine tumors. The highest grade in this classification scheme (Enneking's 3) should be given to all patients in this study (Fig. 1).

\section{Tomita's Classification}

Eighty percent of patients (35) were classified with Tomita's grade 7 (involvement of multiple vertebrae (Fig. 7)).

Seventeen percent of patients (8 out of 516) were assigned to Tomita's Grade 6 (involvement of two or three vertebrae), and only one patient ( $2 \%$ ) was designated with Tomita's grade 5 (single level with paravertebral and spinal canal involvement) (Fig. 8). Only one patient presented with a Tomita grade 1 vertebral level of tumor invasion. Two patients presented with two levels, five patients with three 
levels, five patients with four levels, one patient with five levels and 30 patients with more than 5 levels.

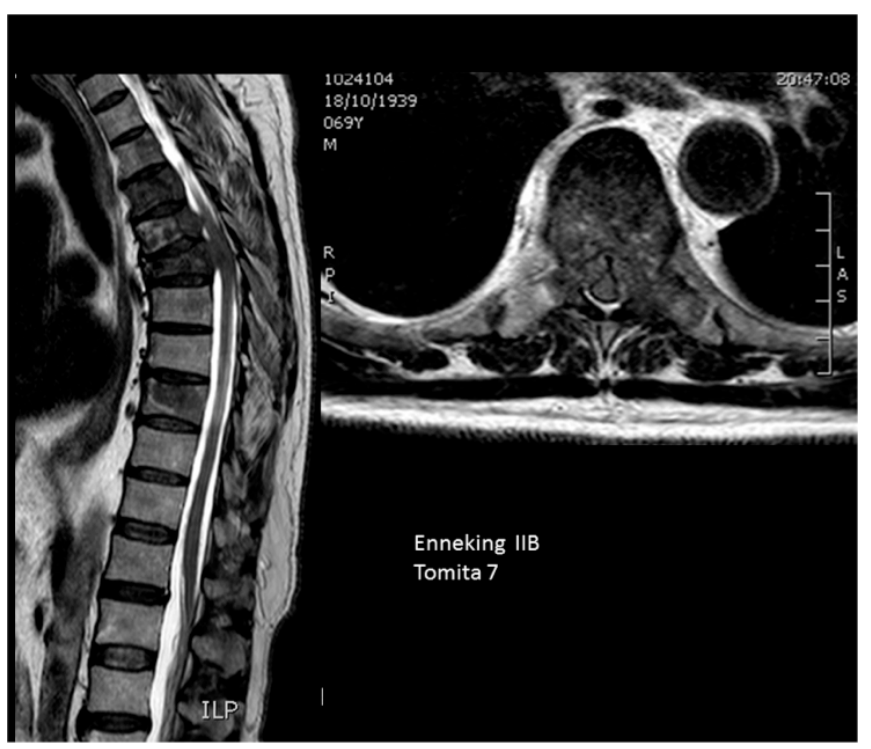

Fig. (6). Multiple vertebral involvement (Tomita's grade 7).

The spinal canal was invaded in $83 \%$ of the patients, being spared in only 8 patients, in whom metastatic involvement was concentrated in the bone structures.
Forty-five percent $(45 \%)$ of patients were treated conservatively with radiotherapy, and forty-three (43\%) were treated with a decompression-only approach. In 6\% of patients, decompression was combined with spine fixation, and $6 \%$ of patients received only a diagnostic percutaneous biopsy. No patients were treated with radical excision surgery.

\section{DISCUSSION}

Vertebral involvement quantification, vertebral canal invasion, neurological status, general health status and the malignancy prognosis, determined by primary tumor histology, are paramount factors to consider for surgical planning and establishing therapeutic targets. A variety of surgical methods are available to treat spinal metastases. Dorsal spinal decompression and stabilization are the most frequent surgical techniques used to treat metastatic disease of the thoracic and lumbar spine [1, 2, 9, 12, 20-24]. Because $>60 \%$ of spinal metastases are hypervascular, preoperative embolization may also be considered in order to decrease hemorrhage risk and improve outcomes with low complication rates $[25,26]$.

For patients with a solitary spinal metastasis without vertebral canal invasion and who are in good general health with a long life expectancy, ventral tumor resection (en bloc spondylectomy/total vertebrectomy) accompanied with

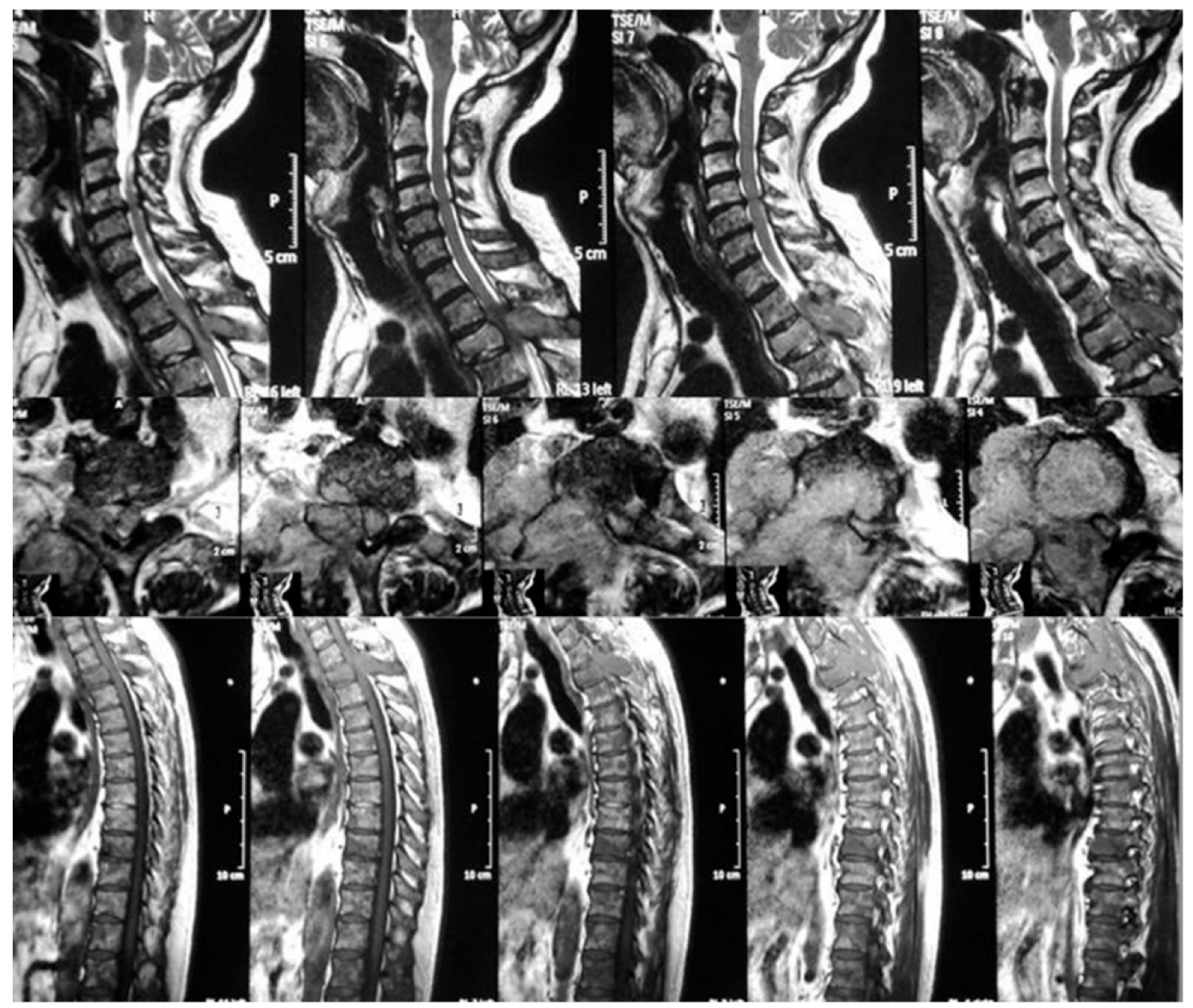

Fig. (7). All spine is involved in vertebral metastasis. 
primary stabilizing instrumentation has been suggested [9, $10,24,27]$.

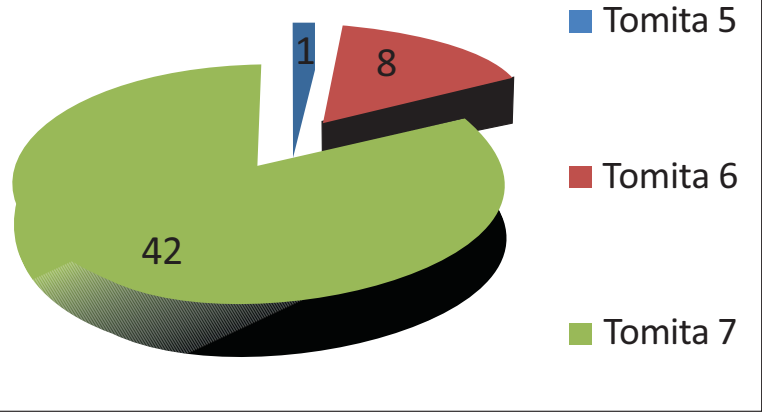

Fig. (8). Classification of patients according to Tomita's vertebral involvement scale.

According to Tomita's study, for patients with a prognostic score of 2 or 3, the treatment goal is long-term local control, with an expected survival period of more than 2 years. For these patients, wide marginal excision (en bloc spondylectomy) is appropriate [16].

When the treatment goal is middle-term local control (prognostic score of 4 or 5 on Tomita's scale), intralesional excision methods such as piecemeal excision or eggshell curettage are the appropriate surgical modalities. For patients with a prognostic score of 6 or 7 , palliative surgery such as spinal cord decompression with stabilization is the first choice for short-term palliation, and when the prognostic score is 8,9 , or 10 , supportive care is advocated [16].

Although several prognostic vertebral metastasis classifications [27-29] have been published, we were able to identify only two classification schemes for quantification of vertebral body involvement [4, 15-19, 30]. Because all patients were consistent with the maximal possible grade in Enneking's classification (considering that a skip metastasis is not an adequate criteria for spine metastasis), this classification does not discriminate between several possible spinal involvements and was not adequate for studying vertebral metastasis. Tomita's classification is the adequate classification to grade spine vertebral metastasis involvement.

Cancer patients with metastases are challenging to treat because metastasis represents an advanced stage of disease and, hence, a poor prognosis $[1-3,9,20,21]$. The majority of the patients in our study presented with poor-to-moderate general health conditions as stratified by KS. In addition, many of the patients $(83 \%)$ presented with involvement of multiple vertebral levels and extensions to the spinal canal.

Almost seventy percent $(69,5 \%)$ of patients presented with some neurologic deficit.

None of the fifty-one patients in our study were found to be candidates for oncologic surgery (radical tumor resection).

However, we have only included patients requiring Hospital admission and a large portion of them were quite ill and/or neurologically impaired. It is possible that an unknown percentage of outpatients may be in better clinical condition and thus be candidates to a more radical surgery.
Therefore, candidates for radical en bloc surgery must exist at a frequency of less than 1/51. Furthermore, due to the nature of vertebral metastasis dissemination, these hypothetical patients can be considered candidates for the surgery for only a short duration of their cancer disease if the primary emboligenic cancer focus is not completely eradicated.

\section{CONCLUSIONS}

Due to diffuse vertebral involvement of metastases no patients in this sample could be considered candidates for radical spondylectomy of vertebral metastasis.

\section{CONFLICT OF INTEREST}

The authors confirm that this article content has no conflict of interest.

\section{ACKNOWLEDGEMENTS}

Declared none.

\section{REFERENCES}

[1] Akbar M, Ayache A, Eichler M, Klotz M, Wiedenhöfer B, Lehner B. Management of spinal metastases, strategies and surgical indications. Orthopade 2012; 41(8): 632-9.

[2] Shiue K, Sahgal A, Chow E, et al. Management of metastatic spinal cord compression. Expert Rev Anticancer Ther 2010; 10(5): 697-708.

[3] Paton GR, Frangou E, Fourney DR. Contemporary treatment strategy for spinal metastasis: the "LMNOP" system. Can J Neurol Sci 2011; 38(3): 396-403.

[4] Choi D, Crockard A, Bunger C, et al. Global Spine Tumour Study Group. Review of metastatic spine tumor classification and indications for surgery: the consensus statement of the Global Spine Tumour Study Group. Eur Spine J 2010; 19(2): 215-22.

[5] Kilbride L, Cox M, Kennedy CM, Lee SH, Grant R Metastatic spinal cord compression: a review of practice and care. J Clin Nurs 2010; 19(13-14): 1767-83.

[6] Polly DW Jr, Chou D, Sembrano JN, Ledonio CG, Tomita K. An analysis of decision making and treatment in thoracolumbar metastases. Spine (Phila Pa 1976) 2009; 15(34): S118-27.

[7] Aizenberg MR, Fox BD, Suki D, McCutcheon IE, Rao G, Rhines LD. Surgical management of unknown primary tumors metastatic to the spine. J Neurosurg Spine 2012; 16(1): 86-92.

[8] Sciubba DM, Petteys RJ, Dekutoski MB et al. Diagnosis and management of metastatic spine disease. J Neurosurg Spine 2010; 13(1): 94-108.

[9] Delank KS, Wendtner C, Eich HT, Eysel P. The treatment of spinal metastases. Dtsch Arztebl Int 2011; 108(5): 71-9; quiz 80.

[10] Murakami H, Kawahara N, Demura S, Kato S, Yoshioka K, Tomita $\mathrm{K}$. Total en bloc spondylectomy for lung cancer metastasis to the spine. J Neurosurg Spine 2010; 13(4): 414-7.

[11] Fehlings MG, David KS, Vialle L, Vialle E, Setzer M, Vrionis FD. Decision making in the surgical treatment of cervical spine metastases. Spine (Phila Pa 1976). 2009; 34(22 Suppl): S108-17.

[12] Bauer HC. Surgical strategy for spinal metastases. Spine 2002; 27 : $1124-1125$.

[13] Hessler C, Burkhardt T, Raimund F, et al. Dynamics of neurological deficit after surgical decompression of symptomatic vertebral metastases. Spine 2009; 34(6): 556-71.

[14] Hessler C, Vettorazzi E, Madert J, Bokemeyer C, Panse J. Actual and predicted survival time of patients with spinal metastasis of lung cancer: evaluation of the robustness of the Tokuhashi score. Spine 2011; 36(12): 983-9.

[15] Enneking WF, Spanier SS, Goodman MA. A system for the surgical staging of musculoskeletal sarcoma. Clin Orthop Relat Res 1980; (153): 106-20.

[16] Tomita K, Kawahara N, Kobayashi T, Yoshida A, Murakami H, Akamaru T. Surgical strategy for spinal metastases. Spine 2001; 26: $298-306$.

[17] McLain RF, Weinstein JN. Tumors of the spine. Semin Spine Surg 1990; 2: 157-80. 
[18] Boriani S, Weinstein JN, Biagini R. Primary bone tumors of the spine: terminology and surgical staging. Spine 1997; 22: 1036- 44.

[19] Harrington KD. Metastatic disease of the spine. J Bone Joint Surg 1986; 68A: 1110-5.

[20] Hirabayashi H, Ebara S, Kinoshita T, et al. Clinical outcome and survival after palliative surgery for spinal metastases: palliative surgery in spinal metastases. Cancer 2003; 97: 476-84.

[21] Itshayek E, Yamada J, Bilsky M, et al. Timing of surgery and radiotherapy in the management of metastatic spine disease: a systematic review. Int J Oncol 2010; 36(3): 533-44.

[22] Chataigner H, Onimus M. Surgery in spinal metastasis without spinal cord compression: indications and strategy related to the risk of recurrence. Eur Spine J 2000; 9(6): 523-7.

[23] Klekamp J, Samii H. Surgical results for spinal metastases. Acta Neurochir (Wien) 1998; 140(9): 957-67.

[24] Demura S, Kawahara N, Murakami H, et al. Total en bloc spondylectomy for spinal metastases in thyroid carcinoma. J Neurosurg Spine 2011; 14(2): 172-6.

[25] Truumees E, Dodwad SN, Kazmierczak CD. Preoperative embolization in the treatment of spinal metastasis. J Am Acad Orthop Surg 2010; 18(8): 449-53.
[26]

Schirmer CM, Malek AM, Kwan ES, Hoit DA, Weller SJ. Preoperative embolization of hypervascular spinal metastases using percutaneous direct injection with n-butyl cyanoacrylate: technical case report. Neurosurgery 2006; 59(2): E431-2; author reply E4312.

[27] Leithner A, Radl R, Gruber G, et al. Predictive value of seven preoperative prognostic scoring systems for spinal metastases. Eur Spine J 2008; 17(11): 1488-95.

[28] Wibmer C, Leithner A, Hofmann G, et al. Survival analysis of 254 patients after manifestation of spinal metastases: evaluation of seven preoperative scoring systems. Spine (Phila Pa 1976) 2011; 36(23): 1977-86.

[29] Papastefanou S, Alpantaki K, Akra G, Katonis P. Predictive value of Tokuhashi and Tomita scores in patients with metastatic spine disease. Acta Orthop Traumatol Turc 2012; 46(1): 50-6.

[30] Comey $\mathrm{CH}$, McLaughlin MR, Moossy J. Anterior thoracic corpectomy without sternotomy: a strategy for malignant disease of the upper thoracic spine. Acta Neurochir (Wien) 1997; 139(8): 7122.

(C) Botelho et al.; Licensee Bentham Open.

This is an open access article licensed under the terms of the Creative Commons Attribution Non-Commercial License (http://creativecommons.org/licenses/by-nc/3.0/) which permits unrestricted, non-commercial use, distribution and reproduction in any medium, provided the work is properly cited. 